The copy is the accepted version by LNEE. The publisher's version is available on SpringerLink: https://link.springer.com/chapter/10.1007/978-981-10-5768-7_46

\title{
Improving the Decision-making of Reverse Logistics Network Design Part I: A MILP Model under Stochastic Environment
}

\author{
Hao Yu' ${ }^{1}$, Wei Deng Solvang ${ }^{2}$
}

\begin{abstract}
The study of the network design problems related to reverse supply chain and reverse logistics is of great interest for both academicians and practitioners due to its important role for a sustainable society. However, reverse logistics network design is a complex decision-making problem that involves several interactive factors and faces many uncertainties. Thus, in order to improve the reverse logistics network design, this paper proposes a new optimization model under stochastic environment and an improved solution method for network design of a multi-stage multi-product reveres supply chain. The study is presented in a series of two parts. Part I presents the relevant literature and formulates a stochastic mixed integer linear programming (MILP) for improving the decision-making of the reverse logistics network design. Part II improves the solution method for the proposed stochastic programming and illustrates the application through a numerical experimentation.
\end{abstract}

Keywords: Reverse logistics, network design, operational research, optimization, stochastic programming, MILP, scenario-based solution, risk averse

\subsection{Introduction}

Supply chain management is a well-understood and well-developed concept, and it has been extensively focused due to its significant role in determining the success of a company. As argued by Chopra and Meindl (2007), in today's dynamic and competitive marketplace, the competition is no longer a company versus company

\footnotetext{
${ }^{1} \mathrm{H} . \mathrm{Yu}(\bowtie)$

Department of Industrial Engineering, UiT The Arctic Univeristy of Norway, Lodve

Langesgate 2, 8514 Narvik, Norway

e-mail: hao.yu@uit.no

2 W.D. Solvang

e-mail: wei.d.solvang@uit.no
}

Cite this paper: Yu H., Solvang W.D. (2018) Improving the Decision-Making of Reverse Logistics Network Design Part I: A MILP Model Under Stochastic Environment. Lecture Notes in Electrical Engineering, vol 451, 431-438. Doi: 10.1007/978-981-10-5768-7_46 
game, but it is a competition between different supply chains. Thus, the design of an effective supply chain is of great importance for a company to survive in the market and gain profit (Moncayo-Martínez and Mastrocinque, 2016). Traditionally, the focus of supply chain management is to manage the material, cash and information flow from the raw material suppliers, via manufacturers, distributors and/or retailers, towards the end customers in order to generate profits through the fulfilment of customer demands (Chopra and Meindl, 2007, Hugos, 2011). The primary objective of such supply chain network design problems becomes therefore profitor cost-focused (Keshavarz Ghorabaee et al., 2017). However, with the increased emphasis on circular economy and sustainable development in recent years, the management of environmental impact of supply chain activities has been gained significant attentions (Beamon, 1999), and new concepts, i.e., green supply chain, reverse logistics, etc., have been introduced and widely accepted by the public as well as that in the research world.

Reverse logistics is one of the most important means for improving the environmental performance of a supply chain through reducing the waste and recovering value from used products (Diabat et al., 2013, Yu and Solvang, 2016). During the latest two decades, the study of the network design problems related to reverse logistics and reverse supply chain has been of significant interest for both academicians and practitioners (Shekarian et al., 2016). Critical literature reviews are given by different researchers to summarize the current development and suggest new directions for future research (Agrawal et al., 2015, Govindan et al., 2015, Pokharel and Mutha, 2009, Mahaboob Sheriff et al., 2012). In this paper, some latest research works in reverse logistics network design are reviewed and the comparison is made with previous review results.

Li et al. (2017) develop a hybrid artificial bee colony algorithm for the network design problem of reverse logistics system, which minimizes the overall system operating costs. Considering the cost-minimization of an integrated forward/reverse logistics system, Tsao et al. (2017) formulate a non-linear mathematical programming incorporating with a continuous approximation method for reverse logistics network design. Zandieh and Chensebli (2016) investigate a water flow like algorithm for minimizing the costs related to the establishment and operation of a reverse logistics system. Taking into account of the cross-docking option in reverse logistics design, Kheirkhah and Rezaei (2016) formulates a mixed integer linear programming (MILP) in order to minimize the overall costs.

Reverse logistics network design usually involves several objectives. Yu and Solvang (2016) propose a bi-objective optimization model with a normalized weighed sum method for sustainable reverse logistics design, which considers the balance of costs and carbon emissions. Yilmaz et al. (2016) develop a bi-objective MILP model for optimal route planning problem of a hazardous waste management system, and it aims at minimizing both costs and environmental risks. Govindan et al. (2016) investigate a fuzzy multi-objective MILP model simultaneously balanc- 
[Type here]

ing the economic, environmental and social sustainability in reverse logistics design. Yu and Solvang (2017) formulate a multi-objective optimization for sustainable design of a municipal solid waste (MSW) management system.

Decision-making under inexact input information is another well-focused topic in reverse logistics network design. Keshavarz Ghorabaee et al. (2017) investigate a two stage decision-making system for designing an integrated forward/reverse logistics system under uncertainties. Soleimani and Govindan (2014) develops a stochastic optimization model for reverse logistics network design considering the minimization of risk in decision-making. Talaei et al. (2016) propose a robust fuzzy optimization model to account both cost and carbon emission of reverse logistics design under uncertainties.

In the real world, decision-making is never done with all necessary information available (King and Wallace, 2012). Therefore, it is of significance to develop advanced tool for decision-making of reverse logistics network design with inexact information. This paper investigates a new MILP model under stochastic environment for reverse logistics network design, and the generation of used products and price for recycled products are formulated as stochastic parameters. The study is presented in a series of two parts. Part I formulates the mathematical model. Part II improves the solution method and illustrates the application through a numerical experimentation.

\subsection{Problem and Modeling}

This paper focuses on an open-loop supply chain network structure as presented in Yu et al. (2016). Fig.1 illustrates that the reverse logistics system includes four levels of nodes: end customer, collection \& dissembling center, reuse/repair center, recycling center and waste disposal plant, respectively. As can be seen in the figure, the flow of used products in the open-loop reverse logistics system starts from the end customers, via intermediate nodes for collection, disassembly, repair and recycling, towards different primary and secondary markets for value recover and landfills for proper disposal.

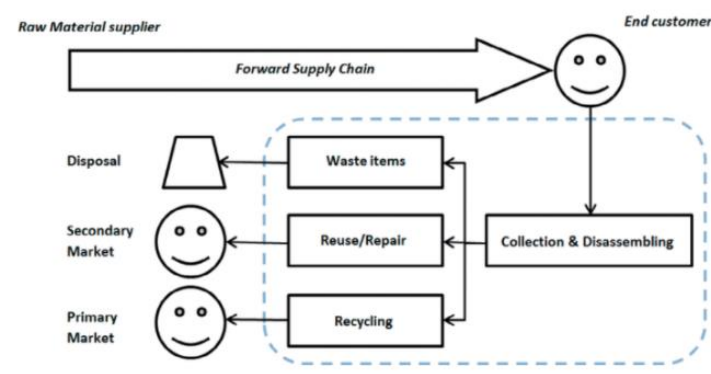

Fig. 1.1 The structure of reverse logistics network (Yu et al., 2016). 
It is a prerequisite that the relevant parameters are known or can be estimated for decision-making. Moreover, in order to formulate the problem, the notations of the indices, sets, parameters, decision variables are first given in Table 1.

Table 1.1 Notations of indices, sets parameters and decision variables used in the formulation of the mathematical model

\begin{tabular}{|c|c|}
\hline \multicolumn{2}{|l|}{ Sets and indices } \\
\hline$S$ & Set of scenarios, $s \in S$ \\
\hline$P$ & Set of products, $p \in P$ \\
\hline$M$ & Set of markets/customers, $m \in M$ \\
\hline$C$ & Set of potential locations for collection centers, $c \in C$ \\
\hline$J$ & Set of potential locations for repair centers, $j \in J$ \\
\hline K & Set of potential locations for recycling centers, $k \in K$ \\
\hline$L$ & Set of disposal centers, $l \in L$ \\
\hline \multicolumn{2}{|l|}{ Parameters } \\
\hline \multirow{2}{*}{$\begin{array}{l}F_{c}, F_{j}, F_{k} \\
V_{c p}, V_{j p}, V_{k p}\end{array}$} & Fixed costs for collection center $c$, repair center $j$ and recycling center $k$ \\
\hline & $\begin{array}{l}\text { Variable costs at collection center } c \text {, repair center } j \text { and recycling center } \\
k\end{array}$ \\
\hline$V_{l p}$ & Treatment costs at established disposal center $l$ \\
\hline$T_{m c p}$ & $\begin{array}{l}\text { Unit costs for first level transportation of product } p \text { between customer } m \\
\text { and collection center } c\end{array}$ \\
\hline$T_{c j p}, T_{c k p}, T_{c l p}$ & $\begin{array}{l}\text { Unit costs for second level transportation of product } p \text { between collec- } \\
\text { tion center } c \text { and repair center } j \text {, between collection center } c \text { and recy- } \\
\text { cling center } k \text {, and between collection center } c \text { and disposal center } l\end{array}$ \\
\hline \multirow{3}{*}{$\begin{array}{l}W_{m p s} \\
C R_{p j}, C R_{p k} \\
B_{c p}, B_{j p}, B_{k p}\end{array}$} & Generation of used products $p$ at customer $m$ in scenario $s$ \\
\hline & Reusable and recyclable fractions of product $p$ \\
\hline & $\begin{array}{l}\text { Planned capacity of collection center } c \text {, repair center } j \text { and recycling cen- } \\
\text { ter } k \text { for product } p\end{array}$ \\
\hline \multirow{2}{*}{$\begin{array}{l}S P_{p j s}, S D_{p j s} \\
S P_{p k s}, S D_{p k s}\end{array}$} & Profit and government subsidy for repairing one unit of product $p$ \\
\hline & Profit and government subsidy for recycling one unit of product $p$ \\
\hline \multicolumn{2}{|c|}{ Decision variables } \\
\hline$\vartheta_{c s}, \vartheta_{j s}, \vartheta_{k s}$ & $\begin{array}{l}\text { First stage decision variables determining if the potential locations for } \\
\text { collection center, repair center and recycling center are opened in sce- } \\
\text { nario s }\end{array}$ \\
\hline$A M_{\text {mcps }}$ & $\begin{array}{l}\text { Quantity of first level transportation of used products } p \text { between cus- } \\
\text { tomer } m \text { and collection center } c \text { in scenario } s\end{array}$ \\
\hline $\begin{array}{l}A M_{\text {cjps }}, A M_{\text {ckps }} \\
A M_{\text {clps }}\end{array}$ & $\begin{array}{l}\text { Quantity of first level transportation of used products } p \text { between collec- } \\
\text { tion center } c \text { and repair center } j \text {, between collection center } c \text { and recy- } \\
\text { cling center } k \text {, and between collection center } c \text { and disposal center } l \text { in } \\
\text { scenario } s\end{array}$ \\
\hline
\end{tabular}


[Type here]

\subsubsection{Constraints}

The primary function of reverse logistics is to properly reuse, recycle, treat and dispose the used products, so Eq.(1) guarantees the used products from all customers/markets are collected.

$$
\sum_{c \in C} A M_{m c p s}=W_{m p s}, \forall m \in M, p \in P, s \in S
$$

The equilibrium constraints are formulated in Eqs. (2)-(4). Eq. (2) ensures the input amount of used products from all customers equals to the output amounts for repair, recycling and disposal. Constraints (3) and (4) are to guarantee the amounts of used products sent for reuse and recycling are less than or equal to the respective fractions, which means the components distributed to different facilities must be complied with the reuse/recycling technologies implemented.

$$
\begin{gathered}
\sum_{m \in M} A M_{m c p s}=\sum_{\in C, p \in P, s \in S} A M_{c j p s}+\sum_{k \in K} A M_{c k p s}+\sum_{l \in L} A M_{c l p s}, \forall c \\
C R_{p j} \sum_{m \in M} A M_{m c p s} \geq \sum_{j \in J} A M_{c j p s}, \forall c \in C, p \in P, s \in S \\
C R_{p k} \sum_{m \in M} A M_{m c p s} \geq \sum_{k \in K} A M_{c k p s}, \forall c \in C, p \in P, s \in S
\end{gathered}
$$

Capacity limitation constraints are formulated as follows. Eqs. (5)-(8) guarantee the amount of different types of used products treated at repair center, recycling center and disposal center are less than or equal to the respective capacities. The influence of product type is negligible when they are sent to landfills.

$$
\begin{gathered}
\sum_{m \in M} A M_{m c p s} \leq \vartheta_{c S} B_{c p}, \forall c \in C, p \in P, s \in S \\
\sum_{c \in C} A M_{c j p s} \leq \vartheta_{j s} B_{j p}, \forall j \in J, p \in P, s \in S \\
\sum_{c \in C} A M_{c k p s} \leq \vartheta_{k s} B_{k p}, \forall k \in K, p \in P, s \in S \\
\sum_{c \in C} \sum_{p \in P} A M_{c l p s} \leq B_{l}, \forall l \in L, s \in S
\end{gathered}
$$

Eqs. (9) and (10) are constraints for binary and non-negative decision variables.

$$
\vartheta_{c s}, \vartheta_{j s}, \vartheta_{k s} \in\{0,1\}, \forall c \in C, j \in J, k \in K, s \in S
$$




\subsubsection{Objective function}

The objective of the reverse logistics network design is to maximize the total profits generated. In order to improve the enthusiasm of companies to take part in the reverse logistics, the influence of government subsidy is taken into consideration in this model, so the total revenue of the reverse logistics system is comprised of both sales revenue and subsidy.

$$
\begin{aligned}
& \text { Profit }=\text { Revenue }- \text { Cost, } s \in S \\
\text { Revenue } & =\sum_{c \in C} \sum_{p \in P} \sum_{j \in J}\left(S P_{p j s}+S D_{p j s}\right) A M_{c j p s} \\
& +\sum_{c \in C} \sum_{p \in P} \sum_{k \in K}\left(S P_{p k s}+S D_{p k s}\right) A M_{c k p s}, s \in S \\
\text { Cost } & =\sum_{c \in C} F_{c} \vartheta_{c s}+\sum_{j \in J} F_{j} \vartheta_{j s}+\sum_{k \in K} F_{k} \vartheta_{k s} \\
& +\sum_{m \in M} \sum_{c \in C} \sum_{p \in P} V_{c p} A M_{m c p s}+\sum_{c \in C} \sum_{j \in J} \sum_{p \in P} V_{j p} A M_{c j p s} \\
& +\sum_{c \in C} \sum_{k \in K} \sum_{p \in P} V_{k p} A M_{c k p s}+\sum_{c \in C} \sum_{d \in D} \sum_{p \in P} V_{d p} A M_{c l p s} \\
& +\sum_{m \in M} \sum_{c \in C} \sum_{p \in P} T_{m c p} A M_{m c p s}+\sum_{c \in C} \sum_{j \in J} \sum_{p \in P} T_{c j p} A M_{c j p s} \\
& +\sum_{c \in C} \sum_{k \in K} \sum_{p \in P} T_{c k p} A M_{c k p s}+\sum_{c \in C} \sum_{d \in D} \sum_{p \in P} T_{c l p} A M_{c l p s},
\end{aligned}
$$

The objective function of the proposed model is given in Eqs. (11)-(13). Eq. (11) shows the overall profit of the reverse logistics system equals to the total revenue minus total costs. Eq. (12) calculates the total revenue from the product recovery and government subsidy. Eq. (13) calculates the total cost for establishing and operating the reverse logistics system including facility opening costs, variable costs and transportation costs. The optimal solution to the MILP model under stochastic environment is not the optimal solution to a single scenario but the one with the best profit expectation through all the scenarios. 
[Type here]

\subsection{Summary}

With the increasing focus on the circular economy and sustainable development all over the world, the research on reverse logistics has become a highly focused topic. In this paper, relevant research works recently published are first reviewed and then a new MILP model under stochastic environment is formulated in order to improve the decision-making of reverse logistics network design under inexact input information. In this model, the generation of used products at different markets/customers and the price for recycled products are considered as stochastic parameters. This research is presented in a series of two parts. In the second part, the proposed MILP model under stochastic environment is resolved by an improved multi-criteria scenario-based solution method, and the application of the model is illustrated through a numerical experimentation.

\subsection{Reference}

AGRAWAL, S., SINGH, R. K. \& MURTAZA, Q. 2015. A literature review and perspectives in reverse logistics. Resources, Conservation and Recycling, 97, 76-92.

BEAMON, B. M. 1999. Designing the green supply chain. Logistics information management, 12, 332342

CHOPRA, S. \& MEINDL, P. 2007. Supply chain management. Strategy, planning \& operation. Das summa summarum des management, 265-275.

DIABAT, A., KANNAN, D., KALIYAN, M. \& SVETINOVIC, D. 2013. An optimization model for product returns using genetic algorithms and artificial immune system. Resources, Conservation and Recycling, 74, 156-169.

GOVINDAN, K., PAAM, P. \& ABTAHI, A.-R. 2016. A fuzzy multi-objective optimization model for sustainable reverse logistics network design. Ecological Indicators, 67, 753-768.

GOVINDAN, K., SOLEIMANI, H. \& KANNAN, D. 2015. Reverse logistics and closed-loop supply chain: A comprehensive review to explore the future. European Journal of Operational Research, 240, 603-626.

HUGOS, M. H. 2011. Essentials of supply chain management, John Wiley \& Sons.

KESHAVARZ GHORABAEE, M., AMIRI, M., OLFAT, L. \& KHATAMI FIROUZABADI, S. A. 2017. Designing a multi-product multi-period supply chain network with reverse logistics and multiple objectives under uncertainty. Technological and Economic Development of Economy, 23, 520-548.

KHEIRKHAH, A. \& REZAEI, S. 2016. Using cross-docking operations in a reverse logistics network design: a new approach. Production Engineering, 10, 175-184.

KING, A. J. \& WALLACE, S. W. 2012. Modeling with stochastic programming, Springer Science \& Business Media.

LI, J.-Q., WANG, J.-D., PAN, Q.-K., DUAN, P.-Y., SANG, H.-Y., GAO, K.-Z. \& XUE, Y. 2017. A hybrid artificial bee colony for optimizing a reverse logistics network system. Soft Computing, 1-18.

MAHABOOB SHERIFF, K., GUNASEKARAN, A. \& NACHIAPPAN, S. 2012. Reverse logistics network design: a review on strategic perspective. International Journal of Logistics Systems and Management, 12, 171-194.

MONCAYO-MARTÍNEZ, L. A. \& MASTROCINQUE, E. 2016. A multi-objective intelligent water drop algorithm to minimise cost Of goods sold and time to market in logistics networks. Expert Systems with Applications, 64, 455-466. 
POKHAREL, S. \& MUTHA, A. 2009. Perspectives in reverse logistics: a review. Resources, Conservation and Recycling, 53, 175-182.

SHEKARIAN, E., OLUGU, E. U., ABDUL-RASHID, S. H. \& BOTTANI, E. 2016. A fuzzy reverse logistics inventory system integrating economic order/production quantity models. International Journal of Fuzzy Systems, 18, 1141-1161.

SOLEIMANI, H. \& GOVINDAN, K. 2014. Reverse logistics network design and planning utilizing conditional value at risk. European Journal of Operational Research, 237, 487-497.

TALAEI, M., MOGHADDAM, B. F., PISHVAEE, M. S., BOZORGI-AMIRI, A. \& GHOLAMNEJAD, S. 2016. A robust fuzzy optimization model for carbon-efficient closed-loop supply chain network design problem: a numerical illustration in electronics industry. Journal of Cleaner Production, 113, 662-673.

TSAO, Y.-C., LINH, V.-T., LU, J.-C. \& YU, V. 2017. A supply chain network with product remanufacturing and carbon emission considerations: a two-phase design. Journal of Intelligent Manufacturing, 1-13.

YILMAZ, O., KARA, B. Y. \& YETIS, U. 2016. Hazardous waste management system design under population and environmental impact considerations. Journal of Environmental Management.

YU, H., SOLVANG, W. \& SOLVANG, B. 2016. A multi-objective mathematical programming for sustainable reverse logistics network design. Part I: Model formulation. WIT Transactions on Engineering Sciences, 113, 287-295.

YU, H. \& SOLVANG, W. D. A multi-objective location-allocation optimization for sustainable management of municipal solid waste. Environment Systems and Decisions, 1-20.

YU, H. \& SOLVANG, W. D. 2016. A general reverse logistics network design model for product reuse and recycling with environmental considerations. The International Journal of Advanced Manufacturing Technology, 87, 2693-2711.

ZANDIEH, M. \& CHENSEBLI, A. 2016. Reverse logistics network design: a water flow-like algorithm approach. OPSEARCH, 53, 667-692. 